\title{
Perancangan Sistem Monitoring Perangkat Jaringan Berbasis ICMP dengan Notifikasi Telegram
}

\author{
Petrus Sokibi \\ Sekolah Tinggi Manajemen Informatika dan Komputer CIC Cirebon \\ Jalan Raya Kesambi No. 202 Kota Cirebon Jawa Barat Indonesia \\ Email : petrussokibi@gmail.com
}

\begin{abstract}
Abstrak - Dalam dunia pendidikan sekarang, jaringan komputer merupakan hal yang penting untuk menunjang pembelajaran maupun untuk pertukaran informasi. Monitoring merupakan metode utama untuk menjaga kestabilan jaringan komputer. Proses monitoring jaringan pada SMK NU Kaplongan masih dilakukan secara manual, dengan kompleksnya jaringan yang ada, Network Administrator membutuhkan waktu yang cukup lama untuk menemukan gangguan yang terjadi pada jaringan serta belum lagi dengan faktor Network Administrator yang tidak selalu standby untuk me-monitoring jaringan. Untuk membantu Network Administrator dalam me-monitoring jaringan, penulis akan merancang sistem monitoring perangkat jaringan dengan memanfaatkan protokol ICMP dengan bahasa pemrograman PHP dan MySQL sebagai database-nya serta Bot Telegram untuk pengiriman pesan notifikasi ketika terjadi perangkat yang terputus. Hasil penelitian ini berupa perangkat lunak berbasis web yang berfungsi untuk monitoring perangkat jaringan di lingkungan SMK NU Kaplongan. Sistem monitoring perangkat jaringan ini akan mampu membantu proses monitoring, identifikasi dan perbaikan terhadap gangguan yang terjadi pada jaringan serta membantu Network Administrator dalam menjaga stabilitas jaringan di SMK NU Kaplongan.
\end{abstract}

Kata kunci : monitoring, jaringan, telegram, ICMP, network administrator

\begin{abstract}
In the world of education now, computer network is important to support learning and for information exchange. Monitoring is the main method to maintain the stability of computer networks. Network monitoring process at SMK NU Kaplongan is still done manually, with the complexity of existing network, Network Administrator takes a long time to find the disruption that occurs on the network and not to mention the Network Administrator factor that is not always standby to monitor the network. To assist the Network Administrator in monitoring the network, I will design a network device monitoring system by utilizing the ICMP protocol with PHP and MySQL programming languages as its database and Telegram Bot for notification message delivery when the device is disconnected. The results of this research is a web-based software that serves to monitor network devices in SMK NU Kaplongan. Network monitoring system will be able to assist the process of monitoring, identification and repair of interference that occurs in the network and help Network Administrator in maintaining network stability in SMK NU Kaplongan.
\end{abstract}

Keyword : monitoring, network, telegram, ICMP, network administrator

\section{PENDAHULUAN}

Perkembangan teknologi informasi dan komunikasi saat ini berkembang sangat pesat. Perkembangan tersebut diiringi juga dengan kebutuhan manusia akan teknologi yang semakin meningkat, karena teknologi mampu memberikan kemudahankemudahan bagi penggunanya guna mendukung pekerjaan serta kegiatan sehari-hari. Dengan teknologi, manusia mampu mendapatkan informasi secara cepat dari satu tempat ke tempat yang lain walaupun dengan jarak yang berjauhan.

Monitoring jaringan merupakan kegiatan yang dilakukan untuk memantau setiap perubahan yang terjadi pada perangkat jaringan. Pemantauan jaringan menjadi suatu hal yang cukup sulit dilakukan apabila jaringan pada lingkungan suatu lembaga sudah menjadi sangat luas dan kompleks. Masalah-masalah jaringan yang sering terjadi diantaranya kerusakan perangkat jaringan, kabel jaringan lepas atau putus, adanya serangan (attacker) dari luar, koneksi internet down, dan lain sebagainya. dimana kerusakannya tidak diketahui oleh pemantauan jaringan secara manual dan akan membutuhkan waktu pemeriksaan jaringan yang cukup lama. Disinilah seorang Network Administrator harus mampu menjaga kestabilan dari suatu jaringan.

Monitoring jaringan merupakan metode utama untuk menjaga kestabilitan jaringan. Dengan monitoring, diharapkan jika terjadi permasalahan pada jaringan dapat diketahui dan diperbaiki dengan cepat oleh Network Administrator. Dengan pemanfaatan protokol ICMP dan notifikasi pesan Telegram diharapkan mampu membantu Network Administrator dalam melakukan monitoring perangkat jaringan.

ICMP (Internet Control Message Protocol) merupakan salah satu protokol di dalam jaringan komputer yang umumnya digunakan untuk mengecek 
dan menampilkan adanya pesan kesalahan pada jaringan komputer, terkait dengan koneksi antar komputer di dalamnya. Hasil dari monitoring perangkat jaringan tersebut akan disimpan ke dalam database. Sedangkan untuk notifikasi atau peringatan ketika terjadi gangguan pada sebuah perangkat jaringan akan memanfaatkan aplikasi telegram untuk mengirimkan pesan kepada Network Administrator.

Aplikasi Telegram merupakan aplikasi yang memungkinkan pengguna untuk mengirim pesan dengan cepat dan aman. Telegram dapat mengirim pesan teks, foto, video dan dokumen dalam bentuk (doc, zip, mp3, dan lain sebagainya). Telegram dapat digunakan pada smartphone, tablet, dan bahkan komputer, selain dapat digunakan pada multi platform Telegram juga sangat ringan, mudah dan gratis.

SMK NU Kaplongan merupakan suatu lembaga pendidikan swasta yang berada di bawah naungan Yayasan Darul Ma'arif Kaplongan Indramayu. Selain SMK NU Kaplongan, Yayasan Darul Ma'arif Kaplongan juga menaungi beberapa lembaga pendidikan diantaranya PAUD NU Kaplongan, SD NU Kaplongan, SMP NU Kaplongan, SMP NU Darul Ma'arif Kaplongan, SMA NU Kaplongan, SMK NU Maritim dan Pariwisata Kaplongan, STKIP NU Indramayu dan Pondok Pesantren Darul Ma'arif Kaplongan. Semua lembaga pendidikan tersebut semuanya membutuhkan akses jaringan yang dimana jaringan untuk semua lembaga disentralkan di SMK NU Kaplongan. Sedangkan dalam memonitoring jaringan, seorang Network Administrator masih melakukannya secara manual, yaitu dengan menunggu adanya laporan dari masing-masing lembaga. Setelah mendapat laporan, seorang Network Administrator akan mencari titik gangguan yang terjadi, karena cukup kompleksnya jaringan yang ada, sehingga dibutuhkan waktu yang cukup lama untuk menemukan titik gangguan yang ada.

Permasalahan akan gangguan pada jaringan tidak akan teratasi walaupun sudah memanfaatkan protokol ICMP sebagai metode monitoring jaringan, akan tetapi kestabilan dari suatu jaringan tetap sangat bergantung terhadap ketersediaan dan kecepatan seorang Network Administrator. Selain itu, Network Administrator harus selalu standby untuk memantau perubahan-perubahan yang terjadi pada jaringan. Hal ini yang melatar belakangi penulis dalam merancang suatu sistem monitoring jaringan yang mampu memberikan notifikasi melalui pesan Telegram ketika terjadi gangguan pada jaringan. Sehingga Network Administrator dapat secara cepat untuk melakukan tindakan terhadap gangguan yang ada.

Dari beberapa alasan di atas, untuk membantu dan mempercepat Network Administrator dalam memperbaiki gangguan yang terjadi pada jaringan, penulis akan membahas Perancangan Sistem Monitoring Perangkat Jaringan Berbasis ICMP dengan
Notifikasi Telegram Studi Kasus di SMK NU Kaplongan.

\section{TINJAUAN PUSTAKA}

\section{A. Internet Control Message Protocol (ICMP)}

ICMP (Internet Control Message Protocol) merupakan salah satu protokol di dalam jaringan komputer yang umumnya digunakan untuk mengecek dan menampilkan adanya pesan kesalahan pada jaringan komputer, terkait dengan koneksi antar komputer di dalamnya.

Pada ICMP terdapat dua buah jenis message (pesan) yang ditampilkannya. Kedua jenis pesan teresebut meliputi :

1. ICMP (Internet Control Message Protocol) Query Message

ICMP Query Message merupakan jenis pesan pada ICMP yang berfungsi untuk mengirimkan informasi berkaitan dengan kondisi dari jaringan komputer bersangkutan, ke dalam sebuah query message. Di dalam ICMP query message terdapat tiga bagian utama yang meliputi Echo dan Echo Reply (untuk memeriksa aktif atau tidaknya suatu komputer di dalam jaringan komputer), Address Mask (berhubungan dengan Subnet Mask pada pengalamatan di dalam Network Layer), serta Time Stamp dan Stamp Reply (memberikan informasi mengenai waktu yang diperlukan oleh suatu paket data di dalam pengiriman pada jaringan komputer).

\section{ICMP (Internet Control Message Protocol) Error Message}

ICMP Error Message merupakan jenis pesan pada ICMP yang berfungsi untuk mengirimkan pesan apabila terjadi kesalahan (error) di dalam jaringan komputer. ICMP error message terdiri atas Destination Unreachable (jika jaringan dan atau komputer tujuan tidak dapat dicapai), Time Exceeded (apabila waktu yang diberikan telah habis, dilihat dari TTL), Redirect (untuk pengalihan suatu paket data ke alamat atau komputer penerima yang benar), Source Quence (apabila terjadi proses Congesti berupa pembuangan paket data di dalam jaringan komputer), dan Parameter Problem (untuk permasalahan yang terjadi pada Header IP Packet). [1]

\section{B. Jaringan Komputer}

Jaringan komputer merupakan kumpulan komputer yang terhubung secara fisik dan dapat berkomunikasi satu dengan yang lainnya dengan menggunakan aturan (protocol) tertentu. Mengelola jaringan yang hanya yang terdiri dari beberapa komputer (host) merupakan pekerjaan yang mudah. Namun jaringan tersebut berkembang dan memiliki ratusan bahkan ribuan host, maka mengelola jaringan 
akan menjadi mimpi buruk bagi setiap pengelola jaringan (Administrator Jaringan).

Belum lagi jaringan tersebut menggunakan teknologi yang berbeda-beda, misalnya ada host yang menggunakan teknologi kabel dan host yang menggunakan teknologi nirkabel (wireless). Ditambah lagi ada beberapa host yang harus digunakan oleh pengguna umum (public user) dan beberapa host hanya bisa digunakan pengguna internal (private user).

Untuk mempermudah mengelola jaringan dengan sekala besar tersebut maka jaringan komputer (network) itu harus dipisahkan menjadi beberapa jaringan kecil. Mengatur beberapa jaringan kecil yang penghuninya hanya puluhan host tentu akan lebih mudah dari pada mengatur sebuah jaringan besar yang berisi ratusan bahkan ribuan host. Teknik memisahkan jaringan ini diimplementasikan untuk jaringan lokal (LAN), jaringan sekala menengah (MAN), jaringan sekala besar (WAN / Internet). [10]

\section{Sistem Monitoring}

Monitoring jaringan merupakan bagian dari manajemen jaringan. Hal yang menjadi dasar dari konsep manajemen jaringan adalah tentang adanya perangkat yang melakukan manajemen dan agen atau perangkat yang dimanajemen.

Monitoring jaringan merupakan tugas yang sulit dan merupakan tugas yang sangat penting bagi seorang Network Administrator. Seorang Network Adminstrator selalu berusaha untuk menjaga kelancaran operasi jaringan. Jika jaringan mengalami penurunan kualitas dalam jangka waktu yang singkat saja akan menyebabkan penurunan produktivitas dalam sebuah perusahaan. Dalam hal monitoring jaringan dituntut agar bersifat proaktif daripada reaktif, Network Administator perlu memonitor lalu lintas dan kinerja dari jaringan dan memastikan tidak terjadi pelanggaran keamanan dalam jaringan.

Monitoring dalam hal ini merupakan proses pengumpulan data dari berbagai sumber yang dilakukan secara real time. Tahapan monitoring secara garis besar dibagi menjadi tiga tahap yaitu :

1. Proses di dalam pengumpulan data monitoring

2. Proses di dalam analisis data monitoring

3. Proses di dalam menampilkan data hasil monitoring

Sumber data dalam proses pengumpulan dapat berupa informasi mengenai status hardware, dan lain sebagainya. Proses dalam analisis data dapat berupa pemilihan data dari sejumlah data yang telah terkumpul atau bisa juga berupa manipulasi data sehingga diperoleh informasi yang diharapkan. Sedangkan tahap menampilkan data hasil monitoring menjadi informasi yang berguna di dalam pengambilan keputusan atau kebijakan terhadap sistem yang sedang berjalan dapat berupa sebuah tabel, gambar, kurva, atau animasi. [2]

\section{Aplikasi Telegram}

Telegram adalah sebuah aplikasi yang memungkinkan pengguna atau user untuk mengirim pesan dengan cepat dan aman, selain itu Telegram sangat ringan, mudah dan gratis. Telegram dapat digunakan pada smartphone, tablet dan bahkan komputer.

Telegram untuk platform iOS diluncurkan pada tanggal 14 Agustus 2013. Sedangkan versi alfa untuk platform Android secara resmi diluncurkan pada tanggal 20 Oktober 2013. Untuk $i O S$ dapat berjalan pada versi iOS 6 dan ke atasnya, Android berjalan pada versi Android 4.1 dan ke atasnya, dan Windows Phone. Selain pada smartphone, Telegram juga dapat menggunakan versi Web Telegram atau dengan memasang aplikasi Telegram Desktop untuk sistem operasi Windows, OSX, dan Linux.

Telegram dapat mengirim pesan teks, foto, video dan dokumen dalam jenis apapun (doc, zip, mp3, dan lain sebagainya), serta dapat membuat sebuah grup sampai dengan 20.000 orang anggota atau channel untuk mengirimkan pesan broadcast yang tidak terbatas. Selain itu, Telegram juga mendukung panggilan suara yang telah di enkripsi end-to-end sebagai keamanan tambahan. [11]

Selain keunggulan-keunggulan di atas, salah satu keunggulan telegram yang lainnya adalah fasilitas Bot Telegram. Bot Telegram merupakan akun khusus yang tidak memerlukan nomor telepon tambahan untuk didaftarkan ke Server Telegram. Akun ini berfungsi sebagai antarmuka antara kode program dengan server Telegram. Telegram merupakan salah satu aplikasi yang mendukung adanya bot ini. Dengan adanya bot ini dapat memudahkan pengguna membuat semacam aplikasi chatting. [12]

\section{ANALISA DAN PERANCANGAN}

Proses analisa sistem merupakan langkah pertama pada fase pengembangan sistem sebelum fase perancangan sistem. Analisa sistem dilakukan untuk mengetahui kelebihan dan kekurangan dari sistem yang akan berjalan, hal ini juga dilakukan untuk mengetahui gambaran umum sistem monitoring perangkat jaringan. Menganalisa data merupakan tahap pertama yang dilakukan dalam proses analisa sistem.

\section{A. Analisa Sistem Berjalan}

Analisa sistem yang berjalan ini meliputi data perangkat jaringan, data blok area, topologi yang digunakan, objek penelitian dan sistem monitoring secara manual.

\section{Perangkat Jaringan}

Data perangkat jaringan yang dibutuhkan dalam membangun sistem monitoring ini meliputi data jenis 
perangkat jaringan dan ip address perangkat jaringan yang akan di-monitoring.

Tabel 1. Perangkat Jaringan

\begin{tabular}{clcc}
\hline No & Nama Perangkat & Jumlah & Satuan \\
\hline 1 & Mikrotik Routerboard & 1 & Unit \\
\hline 2 & Acess Point & 20 & Unit \\
\hline 3 & Modem & 3 & Unit \\
\hline
\end{tabular}

\begin{tabular}{llll}
\hline 4 & Switch & 9 & Unit \\
\hline 5 & PC Server & 1 & Unit \\
\hline
\end{tabular}

2. Data Blok Area

Data blok area dalam membangun sistem monitoring perangkat jaringan ini berupa informasi lokasi perangkat jaringan yang akan di-monitoring. 
Tabel 2. Lokasi Perangkat Jaringan

\begin{tabular}{|c|c|c|c|c|c|}
\hline No & Gedung & Ruang & Nama Perangkat & Jumlah & Satuan \\
\hline \multirow[t]{3}{*}{1} & SMK & Server & Mikrotik Routerboard & 1 & Unit \\
\hline & & & PC Server & 1 & Unit \\
\hline & & & Switch & 1 & Unit \\
\hline 2 & & BTS & Access Point & 4 & Unit \\
\hline \multirow[t]{2}{*}{3} & & Kepala Sekolah & Access Point & 1 & Unit \\
\hline & & & Switch & 1 & Unit \\
\hline 4 & & Guru & Access Point & 1 & Unit \\
\hline \multirow[t]{2}{*}{5} & & $\mathrm{TU}$ & Access Point & 1 & Unit \\
\hline & & & Switch & 1 & Unit \\
\hline \multirow[t]{2}{*}{6} & & LAB Komputer 1 & Acess Point & 1 & Unit \\
\hline & & & Switch & 1 & Unit \\
\hline 7 & & LAB Komputer 2 & Access Point & 1 & Unit \\
\hline \multirow[t]{2}{*}{8} & & LAB Komputer 3 & Access Point & 1 & Unit \\
\hline & & & Switch & 1 & Unit \\
\hline 9 & & LAB Komputer 4 & Access Point & 1 & Unit \\
\hline 10 & & Bengkel TSM & Access Point & 1 & Unit \\
\hline 11 & & Bengkel TKR & Access Point & 1 & Unit \\
\hline \multirow[t]{2}{*}{12} & STKIP & BAAK & Access Point & 1 & Unit \\
\hline & & & Switch & 1 & Unit \\
\hline \multirow[t]{4}{*}{13} & Kantor Yayasan & Lobby Kantor & Access Point & 1 & Unit \\
\hline & & & Switch & 1 & Unit \\
\hline & & Aula Yayasan & Access Point & 1 & Unit \\
\hline & & Rapat & Access Point & 1 & Unit \\
\hline \multirow[t]{2}{*}{14} & SMA & TU & Access Point & 2 & Unit \\
\hline & & & Switch & 1 & Unit \\
\hline \multirow[t]{2}{*}{15} & DM Mart & Minimarket & Access Point & 1 & Unit \\
\hline & & & Switch & 1 & Unit \\
\hline
\end{tabular}

\section{Topologi Sistem Berjalan}

Analisa sistem ini menggambarkan topologi jaringan yang digunakan di SMK NU Kaplongan. Adapun topologi jaringan yang ada sebagai berikut : 


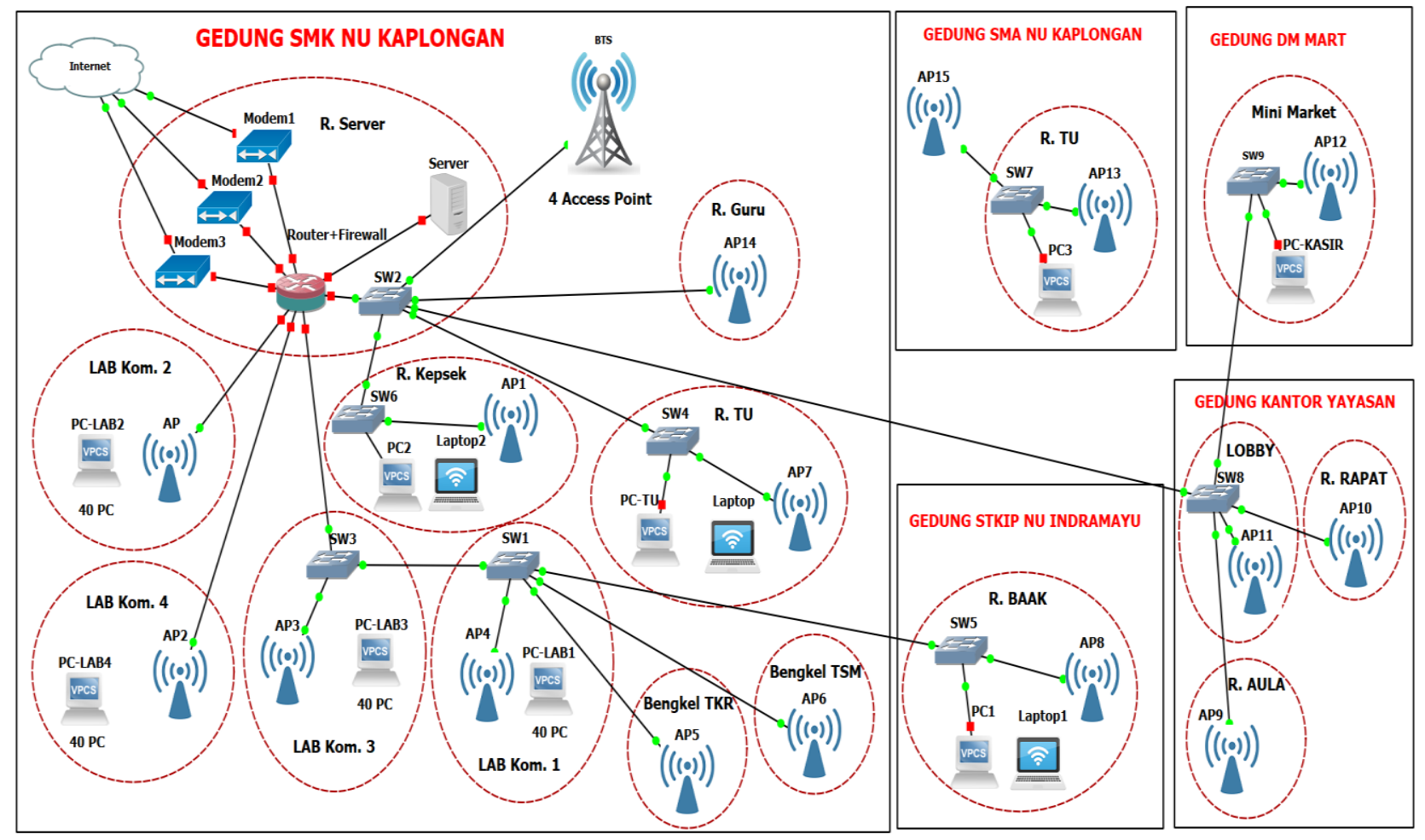

Gambar 1. Topologi Jaringan

\section{Monitoring Sistem Berjalan}

Analisa sistem ini menjelaskan sistem yang berjalan dalam melakukan proses monitoring perangkat jaringan, adapun prosesnya sebagai berikut :

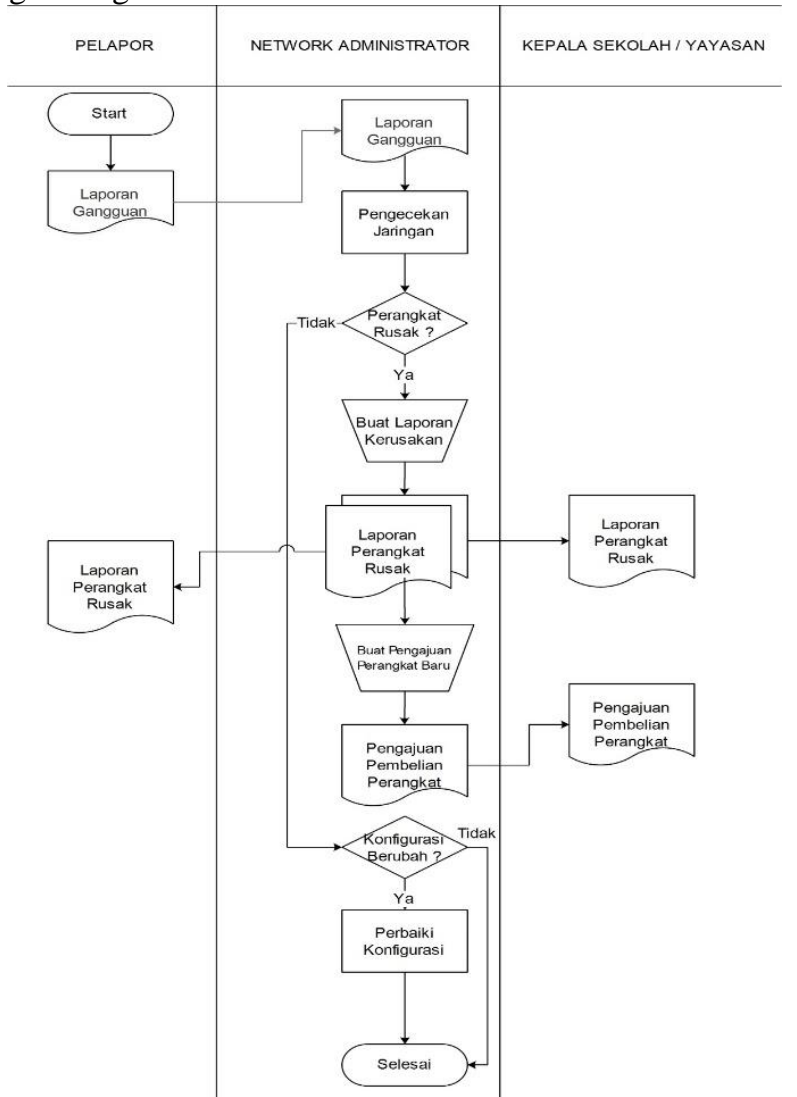

Gambar 2. Proses Sistem Monitoring Berjalan 


\section{B. Analisa Arsitektur Sistem Usulan}

Dalam analisa ini, penulis membuat sistem usulan sebagai berikut :

1. Arsitektur Sistem Monitoring Usulan

Sistem monitoring perangkat jaringan akan mengirimkan pesan notifikasi telegram ketika terdapat gangguan terhadap perangkat jaringan kepada Network Administrator. Gambaran arsitektur monitoring dan pengiriman notifikasi sebagai berikut :

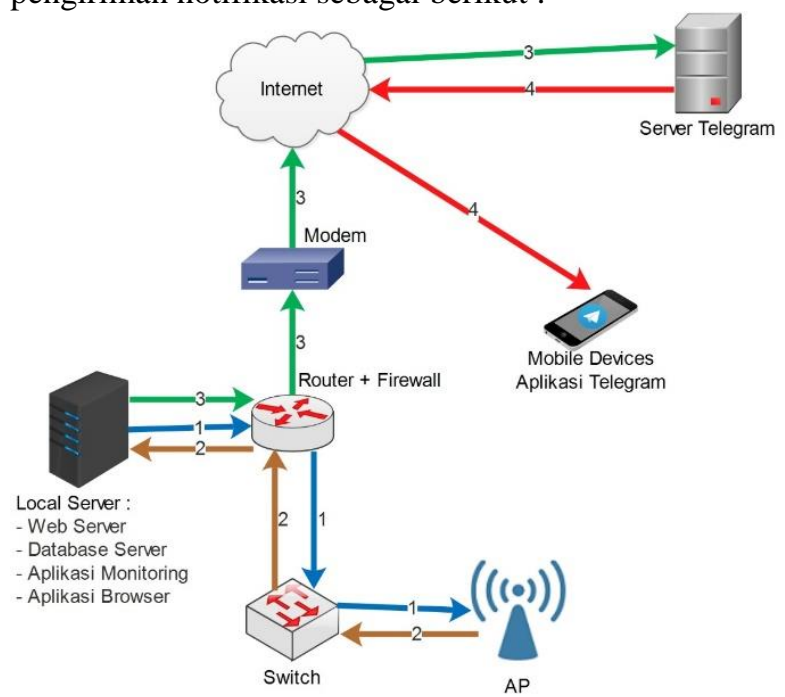

Gambar 3. Arsitektur Sistem Usulan

\section{Monitoring Sistem Usulan}

Monitoring sistem usulan akan dijelaskan melalui diagram flowchart proses monitoring di bawah ini :

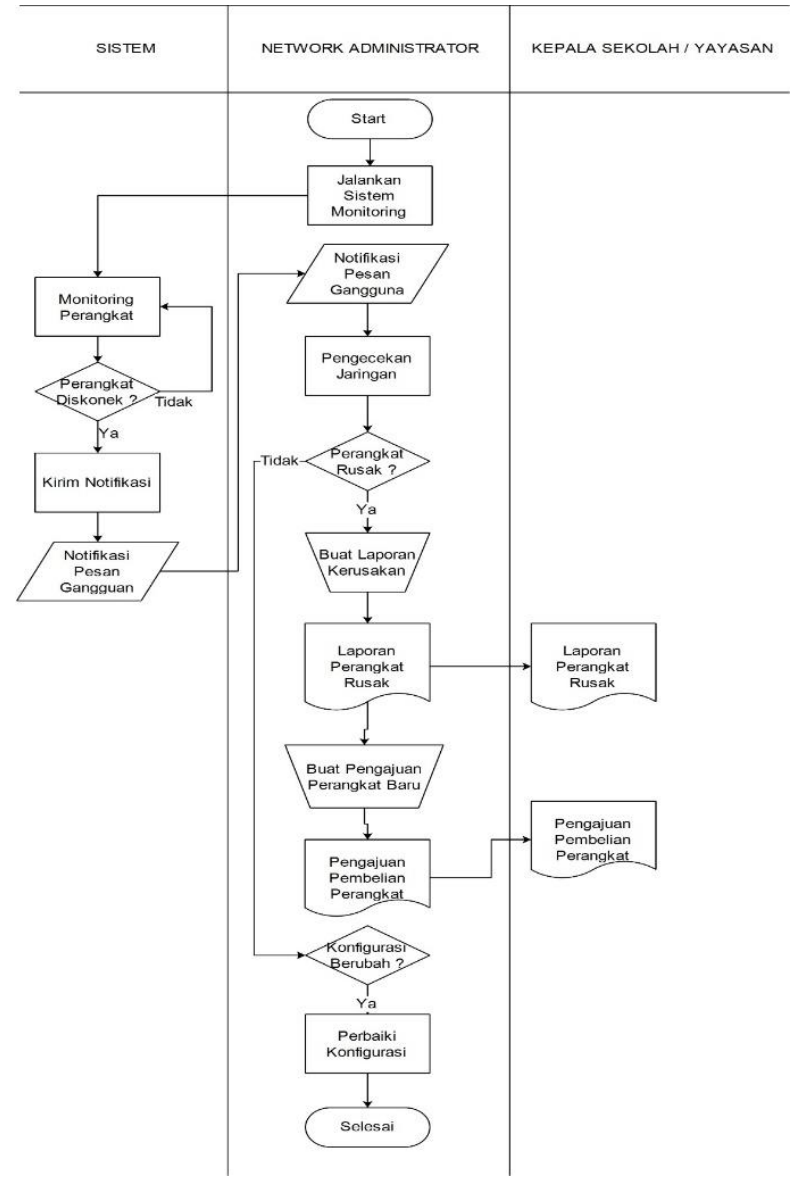

Gambar 4. Monitoring Sistem Usulan

\section{HASIL DAN PEMBAHASAN}

A. Spesifikasi Perangkat Keras (Hardware)

Spesifikasi perangkat keras yang digunakan dalam implementasi sistem monitoring perangkat jaringan ini sebagai berikut :

Tabel 3. Spesifikasi Perangkat Keras

\begin{tabular}{|c|c|c|}
\hline No & $\begin{array}{c}\text { Nama } \\
\text { Perangkat }\end{array}$ & Keterangan \\
\hline 1 & $\begin{array}{l}\text { Komputer } \\
\text { Server }\end{array}$ & $\begin{array}{ll}\text { a. } & \text { CPU Intel Xeon E3-1220 } \\
& \text { V3 3.10GHz } \\
\text { b. } & \text { HDD 500 GB } \\
\text { c. } & \text { RAM 12 GB } \\
\text { d. } & \text { VGA MGA G200EH }\end{array}$ \\
\hline 2 & $\begin{array}{l}\text { Perangkat } \\
\text { Jaringan }\end{array}$ & $\begin{array}{l}\text { Perangkat jaringan yang akan } \\
\text { di-monitoring yaitu Access } \\
\text { Point. }\end{array}$ \\
\hline 3 & $\begin{array}{l}\text { Infrastruktur } \\
\text { Koneksi } \\
\text { Jaringan }\end{array}$ & $\begin{array}{l}\text { Berfungsi sebagai } r \text { alat } \\
\text { konektivitas antara server } \\
\text { dengan perangkat yang di- } \\
\text { monitoring dan juga untuk } \\
\text { mengirimkan } \\
\text { telegram. notifikasi }\end{array}$ \\
\hline
\end{tabular}




\section{B. Spesifikasi Perangkat Lunak (Software)}

Spesifikasi perangkat lunak yang digunakan dalam implementasi sistem monitoring perangkat jaringan sebagai berikut :

Tabel 4. Spesifikasi Perangkat Lunak

\begin{tabular}{cccl}
\hline No & $\begin{array}{c}\text { Nama } \\
\text { Perangkat }\end{array}$ & \multicolumn{1}{c}{ Keterangan } \\
\hline 1 & Sistem Oprasi & Linux Debian 8.0 Jessie \\
\hline \multirow{2}{*}{2} & Server & a. & Web Server (Apache2) \\
& & b. & Database (MySQL) \\
& & Web Browser
\end{tabular}

\section{Implementasi Antar Muka Sistem Monitoring}

Pada implementasi ini, dapat dilihat proses berjalannya sistem monitoring perangkat jaringan baik dalam proses input maupun output. Penjelasannya sebagai berikut :

\section{Form Login}

Form Login ini berfungsi untuk membatasi hak akses ke dalam sistem monitoring perangkat jaringan ini. Network Administrator diharuskan login dengan memasukkan email dan password untuk masuk ke sistem monitoring.

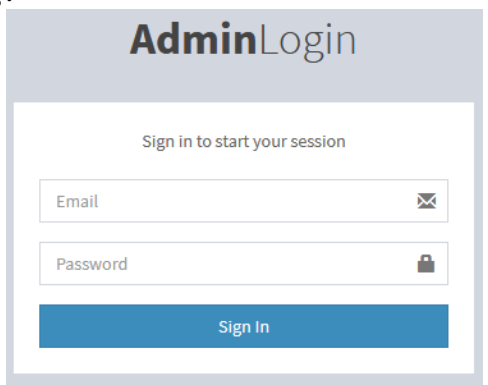

Gambar 5. Form Login

\section{Home Page}

Home Page merupakan halaman awal yang akan ditampilkan setelah berhasil login, juga halaman navigasi untuk masuk ke menu yang lain seperti monitoring, kelola blok area dan perangkat dan $\log$ perangkat.

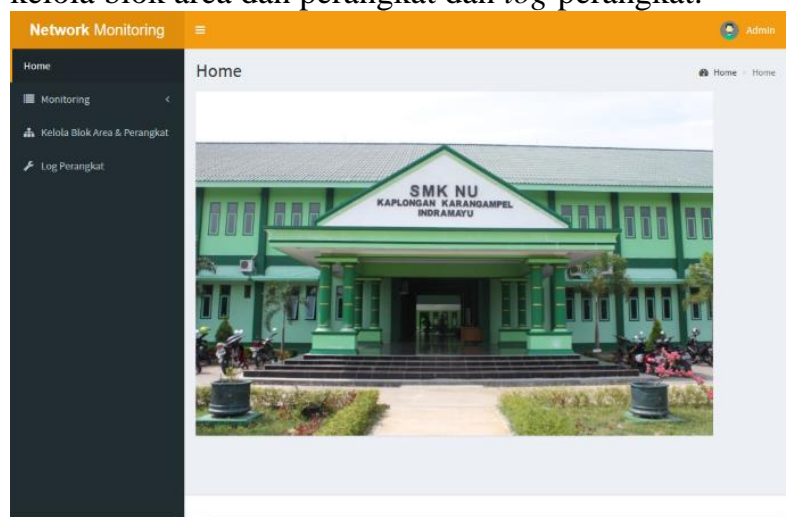

Gambar 6. Home Page
3. Monitoring Page

Monitoring page merupakan halaman yang digunakan dalam proses monitoring perangkat jaringan.

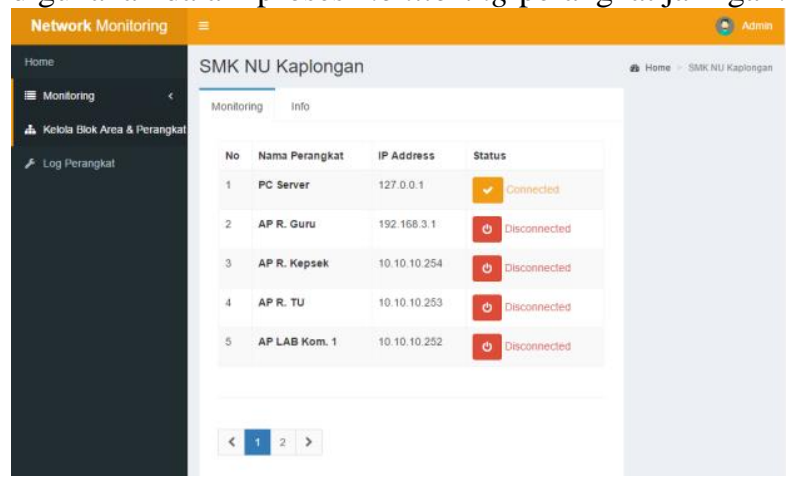

Gambar 7. Monitoring Page

4. Monitoring Info

Halaman info ini merupakan bagian dari halaman monitoring. halaman ini berisikan informasi nama blok area dan jumlah perangkat yang terhubung setiap blok area.

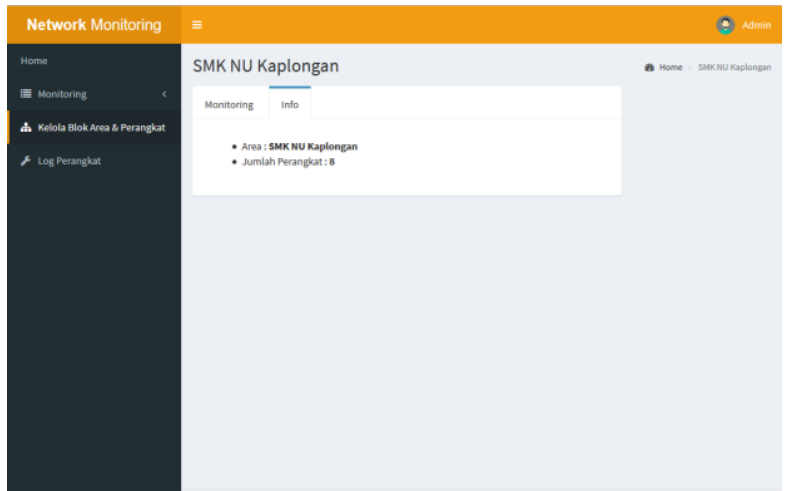

Gambar 8. Monitoring Info

5. Kelola Blok Area dan Perangkat

Halaman kelola blok area dan perangkat merupakan data master blok area dan perangkat, halaman ini berfungsi untuk tambah, edit dan hapus blok area serta perangkat. 


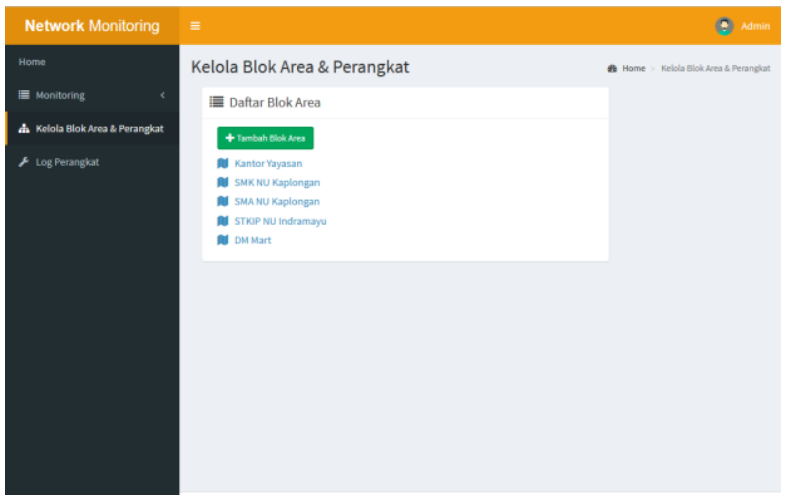

Gambar 9. Kelola Blok Area dan Perangkat

\section{Form Tambah Blok Area}

Form tambah blok area merupakan halaman data master yang digunakan untuk menambah blok area.

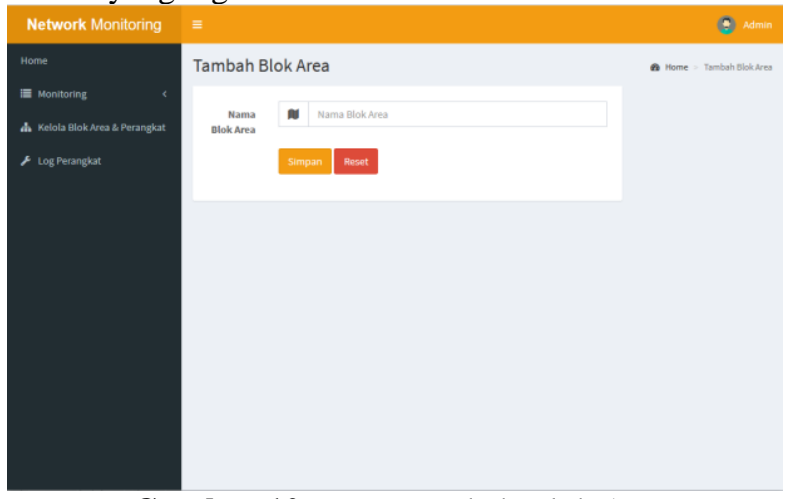

Gambar 10. Form Tambah Blok Area

\section{Kelola Blok Area}

Kelola blok area merupakan bagian dari halaman kelola blok area dan perangkat. Halaman ini juga merupakan data master blok area untuk melakukan edit dan hapus blok area.

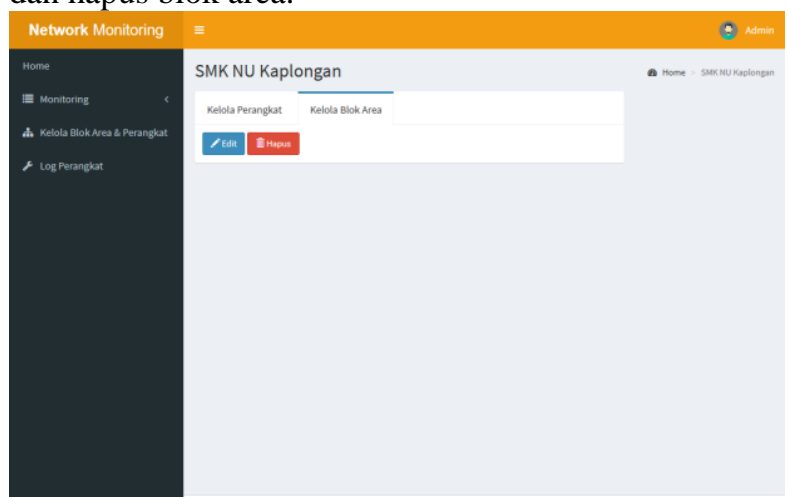

Gambar 11. Kelola Blok Area

\section{Kelola Perangkat}

Halaman kelola perangkat merupakan data master perangkat, pada halaman ini dapat malakukan tambah, edit dan hapus data perangkat.

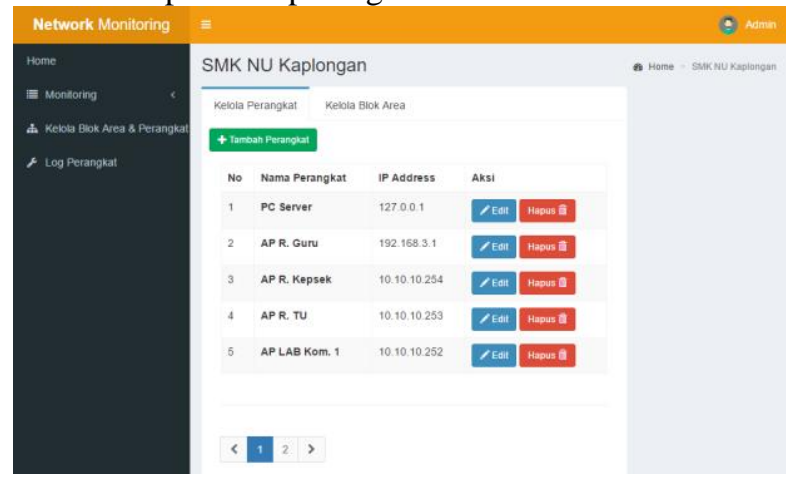

Gambar 12. Kelola Perangkat

\section{Log Perangkat}

Log perangkat merupakan halaman yang berfungsi untuk mencatat semua perangkat yang telah mengalami gangguan.

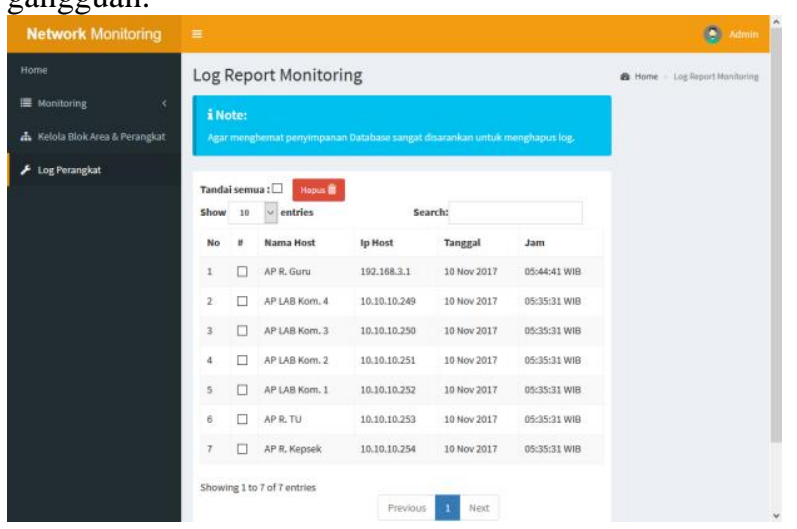

Gambar 13. Log Perangkat

\section{Kirim Notifikasi}

Notifikasi aplikasi telegram berfungsi untuk mengirimkan notifikasi pesan telegram kepada Network Administrator jika tedapat perangkat yang terputus dengan jaringan. 


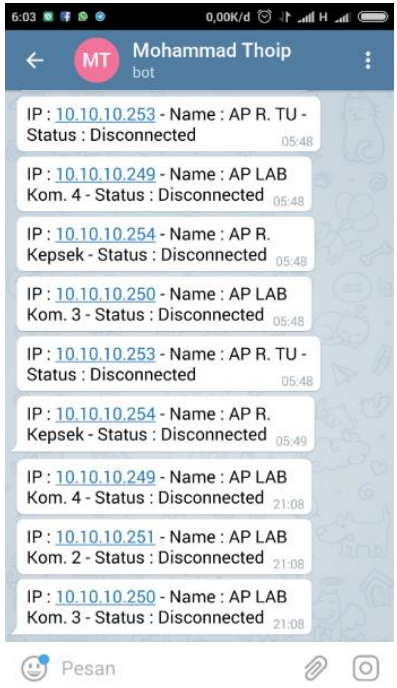

Gambar 14. Kirim Notifikasi

\section{Pengujian Waktu Respon Pengiriman}

\section{Notifikasi}

Pengujian ini dilakukan untuk menguji waktu respon pengiriman notifikasi sistem monitoring dari mulai status perangkat berubah menjadi disconnect sampai dengan notifikasi masuk ke aplikasi telegram Network Administrator.

Tabel 5. Pengujian Waktu Respon Pengiriman Notifikasi

\begin{tabular}{cc}
\hline Pengujian Ke & Waktu Respon \\
\hline 1 & 12 detik \\
\hline 2 & 14 detik \\
\hline 3 & 13 detik \\
\hline 4 & 14 detik \\
\hline 5 & 27 detik \\
\hline Rata-rata & 16 detik \\
\hline
\end{tabular}

Kesimpulan :

1. Pengujian pertama sampai ke empat dilakukan dengan kondisi server dan aplikasi telegram terkoneksi dengan internet.

2. Pengujian ke lima dilakukan dengan kondisi koneksi internet aplikasi telegram terputus namun notifikasi akan tetap dikirim ketika aplikasi telegram telah terhubung dengan internet kembali.

3. Waktu respon pengiriman notifikasi dipengaruhi oleh beberapa faktor diantaranya kualitas koneksi internet dan kondisi perangkat baik server maupun aplikasi telegram itu sendiri. Ketika semua perangkat dan koneksi internet normal maka notifikasi akan dikirim dengan rata-rata waktu lebih kurang 16 detik.

\section{KESIMPULAN}

Kesimpulan yang diambil dari pembuatan Sistem Monitoring Perangkat Jaringan Berbasis ICMP dengan Notifikasi Telegram ini antara lain :

1. Sistem monitoring perangkat jaringan yang dibuat dengan memanfaatkan protokol ICMP ini mampu mempercepat Network Administrator dalam melakukan identifikasi gangguan yang terjadi pada jaringan lokal di SMK NU Kaplongan.

2. Sistem monitoring perangkat jaringan dapat membantu Network Administrator dalam mencari titik gangguan dan memperbaiki gangguan yang terjadi pada jaringan lokal SMK NU Kaplongan.

3. Setiap kali terdapat perangkat yang terputus, maka sistem akan langsung mengirimkan notifikasi pesan telegram kepada Network Administrator. Sehingga mampu membatu Network Administrator dalam menjaga stabilitas jaringan.

4. Komputer server dan mobile aplikasi telegram Network Administrator harus selalu terkoneksi dengan internet, karena proses pengiriman notifikasi pesan telegram hanya akan berjalan jika komputer server dan mobile aplikasi telegram terkoneksi dengan internet.

5. Lama waktu pengiriman notifikasi dari sistem ke aplikasi telegram Network Administrator dipengaruhi oleh beberapa faktor diantaranya koneksi internet dan kondisi perangkat server maupun aplikasi telegram.

\section{DAFTAR PUSTAKA}

[1] Agus Eka Pratama, I Putu. Handbook Jaringan Komputer. Bandung : Informatika, 2014.

[2] Andre Wandi S.P. Siagian. Aplikasi Monitoring Jaringan Berbasis Web dengan Menggunakan Simple Network Management Protocol. Skripsi Teknologi Informasi Fakultas Ilmu Komputer dan Teknologi Informasi Universitas Sumatera Utara Medan, 2014.

[3] Anggoro, S., Sarosa, M. Jaringan Komputer Data Link, Network dan Issue. Teknik Sistem Komputer Elektronik ITB, 2000.

[4] A. S., Rosa dan Shalahudin, M. Rekayasa Perangkat Lunak Terstruktur dan Berorientasi Objek. Bandung : Informatika, 2011.

[5] Betha Sidik, MySQL, Bandung : Informatika, 2003.

[6] Herlawati dan Widodo, Prabowo Pudjo. Menggunakan UML. Bandung : Informatika, 2011.

[7] Nana Syaodih Sukmadinata. Metode Penelitian Pendidikan. Bandung : Rosdakarya, 2009.

[8] Sopandi Dede. Instalasi dan Konfigurasi Jaringan Komputer. Bandung : Informatika, 2008.

[9] Sujadi. Metodologi Penelitian Pendidikan. Jakarta : Rineka cipta, 2003. 
[10] Towidjojo. Mikrotik Kung Fu : Kitab 1. Jakarta : Jasakom, 2012.

[11]

https://core.telegram.org/file/811140327/1/zlN4g oPTupk/9ff2f2f01c4bd1b013, diakses tanggal 26 September 2017

[12] https://telegram.org/faq\#q-what-is-telegram-whatdo-i-do-here, diakses tanggal 26 September 2017 